\title{
Reconstruction of the Maxillofacial Defect after Extensive Resection of the Giant Ameloblastoma Using Osteocutaneous Fibular Free Flap
}

\author{
Duc Quang Nguyen ${ }^{1}$, Son Tai Nguyen ${ }^{1}$, Lam Ngoc Vu${ }^{1}$ and BaekKyu Kim*2 \\ ${ }^{1}$ Military Central Hospital 108, Vietnam \\ ${ }^{2}$ Seoul National University Bundang Hospital, Korea
}

Received: June 06, 2018; Published: June 19, 2018

*Corresponding author: Baek kyu Kim, Department of Plastic and Reconstructive Surgery, Seoul National University Bundang Hospital, Gumi-ro, Seongnam-si, Korea

\begin{abstract}
Extensive resection of a giant ameloblastoma tumor results in a large defect in both bone and skin tissues that poses a major challenge in their reconstruction. AnOsteocutaneous fibular free flap may be suitable for reconstruction of these complex defects. We describe two cases of reconstruction of complex maxillofacial osteocutaneous defects using an osteocutaneous fibular free flap. Postoperatively, the survived free flaps showed good aesthetic results. Hence, an osteocutaneous fibular free flap may be an appropriate choice to reconstruct large and complex multi-component maxillofacial defects.
\end{abstract}

Keywords: Fibular Flap; Giant Ameloblastoma; Reconstruction; Maxillofacial Defect; Osteocutaneous; Masticatory Function; Oral Mucosa; Mandibular Bone; Intraoral Mucosal Defect; Hemorrhagic Ulcers; Peroneal Vascular

\section{Introduction}

Ameloblastoma of the jaws is a benign odontogenic lesion, commonly encountered in the maxillofacial area, in which the mandible is more frequently involved than the maxilla. It is locally invasive with complex clinical and radiographic presentation. Ameloblastoma is a slow-growing, silent, and painless tumor with marginal influences on functions, which is sometimes incidentally detected during regular dental check-up [1,2]. Nonetheless, patients who present late to hospital may have giant tumors that cause unaesthetic deformity of the face, and affect other functions, i.e. eating, mastication, deglutition, and speech. Radical tumor resection leaves large and multi-component defects involving skin, bone or mucosa, making facial reconstruction a challenging task. Here, we present our experience with 2 cases of giant maxillofacial ameloblastoma. The resulting large facial defects after removal of the entire tumors were successfully reconstructed using an osteocutaneous fibular free flap.

\section{Case No. 1}

A 67-year-old male patient who was diagnosed of maxillofacial ameloblastoma 40 years ago. He presented with the deformed right cheek, mandible and mental region, loss of teeth from num ber 48 to 34, complete loss of masticatory function, and difficulty in mandibular movement. The tumor was hard, solid and immobile. The covering skin was thin and overstretched. Numerous ulcerous lesions were found in the oral mucosa surrounding the tumor. CT scan showed the tumor expanding from the right condyle to the left mandibular body, with deformity of the mandibular bone. The surgical plan included complete resection of the tumor, part of the skin and damaged oral mucosa, which was followed by immediate reconstruction using an osteocutaneous fibular free flap.

The surgery was completed with the tumor and the involved part of the mandible from the right condyle to tooth number 35 resected. The size of the mucosal gap was $5 \times 11 \mathrm{~cm}$. The resected tumor size was $19 \times 12 \times 13 \mathrm{~cm}$. We used an osteocutaneous fibular free flap to reconstruct the defect of the lower face. The cutaneous flap was used to cover the mucosal defect while the osseous flap was divided into five segments; one segment for the right ramus, two for the right body, one for the mental region, and one for the left body of the mandibular bone. The segments were shaped to the mandibular angles and affixed by a reconstruction plate to restore the mandibular border. The peroneal arteries and veins of the flap were anastomosed to the facial artery and external jugular vein by 
end-to-end anastomoses, using 10-0 nylon sutures. The osteocutaneous fibular flap covers the intraoral mucosal defect as well. The donor site was primarily closed. The operation lasted 6 hours. Postoperatively, the reshaped flap survived without vascular com- promise. The patient was discharged from hospital after 11 days of treatment. After 2-year follow-up, there was no recurrence of the tumor, the face was symmetrical (Figure 1).

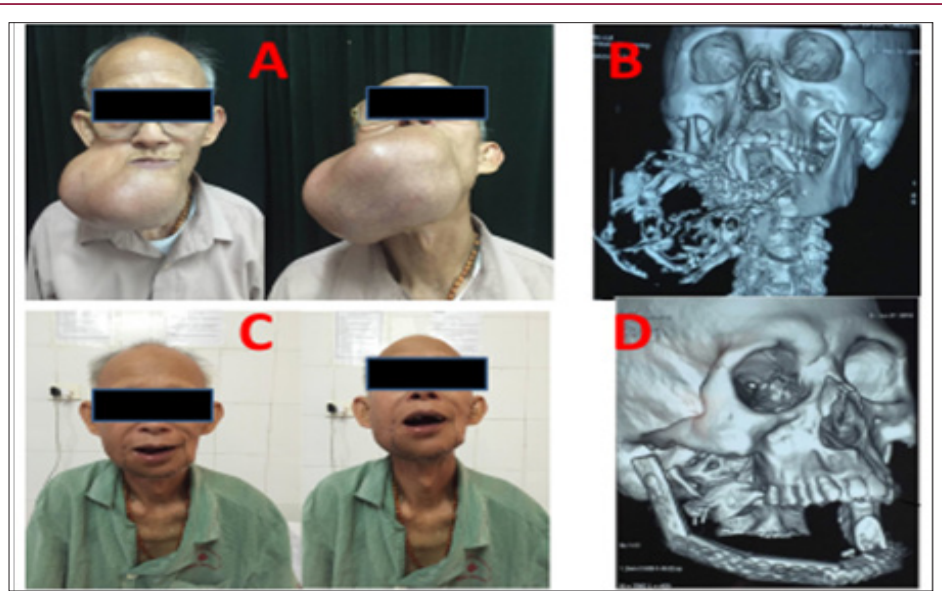

Figure 1: Case No. 1, Before and After Tumor Resection and Facial Reconstruction.

A: Preoperative Images of a Giant Tumor Causing Distortion of the Maxillofacial Area. B: Preoperative CT Scan With 3d Reconstruction of The Tumor. C: Postoperative Images Showing Aesthetic Restoration of the Face. D: Postoperative CT scan with 3D Reconstruction of the Face After Tumor Removal and Reconstruction of the Bones.

\section{Case No. 2}

A 48 years old male patient who was found to have a maxillofacial ameloblastoma 30 years ago. The patient presented with severe deformity of the mid and lower face, being considered inoperable by many hospitals nationwide. The hard, solid and immobile tumor invaded and deformed the nose, blocked the right nostril completely with losses of the right maxillary teeth and masticatory function. The skin on the tumor was in normal condition but multiple hemorrhagic ulcers were found in the oral mucosa surrounding the tumor. CT scans confirmed the invasion of the tumor to the entire maxillary bone and the right palate, invading and damaging the nasal septum. The size of the resected tumor was $10 \times 12 \times 12 \mathrm{~cm}$. The defects for reconstruction included maxillary bones, nasal, palate and buccal mucosa. An osteomusculocutaneous fibula flap was selected that consisted of an $14 \mathrm{~cm}$ long osseous flap harvested along with a cutaneous flap and part of the soleus muscle.
The osseous flap was divided into 2 segments to reconstruct the alveolar bone and the frontal pivot of the maxillary bone. The osteocutaneous fibular flap was set intraorally to cover the oral mucosa and palate, while the soleus muscle was inserted into the maxillary sinus position. The facial skin flap around the tumor was transferred to reconstruct the left nasal mucosa. We anastomosed the peroneal vascular bundles to the superficial temporal artery and vein using end-to-end anastomoses. The donor site of the osteocutaneous fibular flap was covered with skin grafts. The operation lasted 7 hours.Postoperatively, the reconstructive flap survived entirely. The surgical site in the nasal septum had delayed union that required daily dressing and delayed wound closure. The patient was discharged from hospital after 23 days of treatment. There was no recurrence after 3 -year follow-up. The patient was satisfied with the facial shape. The eating, breathing functions and other activities were improved (Figures 2 \& 3 ).

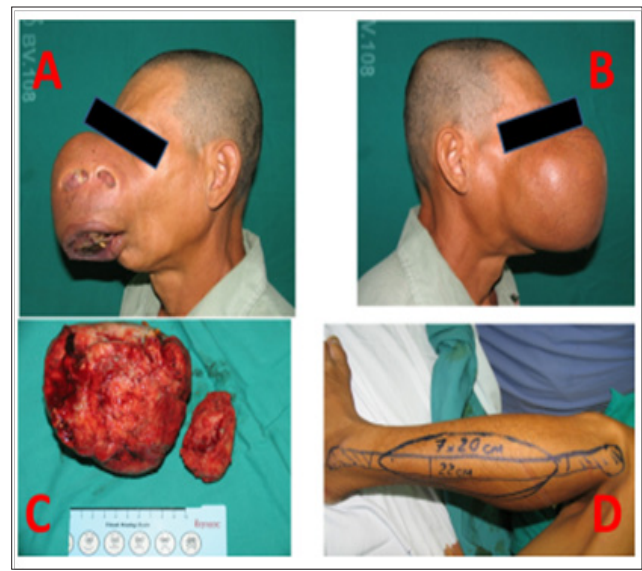

Figure 2: Case No.2, Pre- and Intraoperative Images.

A, B: Preoperative images of the Tumor. C: The Tumor after Removal. D: Design of an Osteocurtaneous Fibula Free Flap for Reconstruction of the Facial Defects after Tumor Removal. 


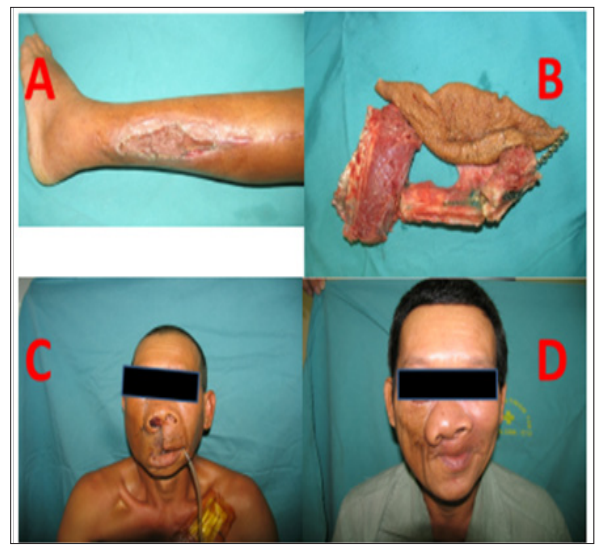

Figure 3: Case No.2, Intra- and Postoperative Images. A: Skin Graft Donor Site Flap. B: Osteomusculocurtaneous Fibula Free Flap. C: 10 days Postoperative. D 2 years Postoperative.

\section{Discussion}

Although ameloblastoma is one of the most common tumors of the maxillofacial area, a giant ameloblastoma tumor is rare and generally seen in underdeveloped countries and regions [3,4]. Both patients in our report were from rural areas with less education. Their first visits to hospital with substantially grown tumors were at least 30 years ago when surgeons did not have reconstructive alternatives to restore the face in case of resecting the tumors, thus they were refused surgery. For example, microsurgical surgery has become popular in Vietnam since 1990 [5]. Recently, reconstruction of large maxilllofacial osseous defects using iliac bone flaps, fibular free flaps has become a main technique to reconstruct maxillofacial osseous defects larger than $5 \mathrm{~cm}$, with or without soft tissue defects.For giant ameloblastoma tumors, radical resection to prevent recurrence poses a great challenge to surgeons, as the true tumor border is always beyond the macroscopic and radiographic boundaries of the lesion [6].

Thus, we always include the bone tissue $1-2 \mathrm{~cm}$ beyond the macroscopic tumor margin to ensure clearance from microscopic infiltration. All involved teeth must be extracted to avoid small tumor islands which may exist within the periodontal ligament.This extensive resection of giant ameloblastoma tumors leave gigantic defects to be reconstructed, which again present another significant challenge. Reconstruction with a fibular free flap could be the best scenario due to its distinct advantages compared to other osseous free flaps such as an iliac flap and scapular flap.In 1975, Taylor et al. reported using the first fibular free flap for a patient with a long bone defect in the extremities [7]. In 1989, Hidalgo reported the application of a fibular free flap in reconstruction of mandibular bone defects [8]. Wei, Schu and Yoshimura's reports confirmed the reliability of a cutaneous flap when harvested along with the fibular osseous flap [9-11].

Fibular osteocutaneous flap have been a suitable choice for complex osteocutaneous lesions.The fibular osseous flap has some advantages: a) It includes a significant amount of bone tissue,

b) It could be divided into multiple segments to fit various shapes of lesions without affecting its blood supply,

c) The flap can be harvested in an osteocutaneous or osteomusculocutaneous fashion according to each complex defect. Currently, a fibular free flap is still the first choice in reconstruction of large mandibular bone defects. This flap is also widely preferred by surgeons for restoration of maxillary defects [12]. Along with a reconstructed bone frame, the both patient's faces have been restored to virtually normal.

\section{Conclusion}

Radical removal of a giant ameloblastoma tumor and subsequent reconstruction of the resulting defects are major challenges. Experiences with the two cases show that one-phase strategy combining extensive resection of the tumor and immediate reconstruction of the defects using a fibular osteocutaneous free flap has yielded favorable outcomes with complete removal of the tumor, aesthetic restoration, functional improvement and better quality of life.

\section{References}

1. Abouda M, Turki S, Billil K (2016) Giant Mandibular Ameloblastoma. Am J Med Sci 352(2): 223.

2. Salami A, Anzouan Kacou E, Assouan C, N'Guessan ND (2016) Giant ameloblastoma. Br J Oral Maxillofac Surg 54(9): 1054-1055.

3. Gravvanis A, Koumoullis HD, Anterriotis D, Tsoutsos D, Katsikeris N (2016) Recurrent giant mandibular ameloblastoma in young adults. Head Neck 38(1): E1947-E1954.

4. Choudhary K, Shah H, Panda S, Gandhi S (2014) Giant ameloblastoma: A rarity. Indian J Cancer 51(4): 592-593.

5. Merrell JC, Tien NV, Son NT, An LN, Sellers D, et al. (2007) Introduction of microsurgery in Vietnam by a charitable organization: a 15-year experience. Plast Reconstr Surg 119(4): 1267-1273.

6. Chaine A, Pitak Arnnop P, Dhanuthai K, Ruhin Poncet B, Bertrand J Ch, et al. (2009) A treatment algorithm for managing giant mandibular ameloblastoma: 5-year experiences in a Paris university hospital. European Journal of Surgical Oncology. WB Saunders 35(9): 999.

7. Taylor GI, Miller GDH, Ham FJ (1975) The free vascularized bone graft: a clinical extension of microvascular techniques. Plastic and Reconstructive Surgery 55(5): 533-544.

8. Hidalgo DA (1989) Fibula free flap: A new method of mandible reconstruction. Plastic and Reconstructive Surgery 84(1): 71-79.

9. Wei FC, Seah CS, Tsai YC (1994) Fibula osteoseptocutaneous flap for reconstruction of composite mandibular defects. Plastic and Reconstructive Surgery 93(2): 294-304.

10. Schusterman MA, Reece GP,Miller MJ, Harris S (1992) The osteocutaneous free fibular flap: Is the skin paddle reliable? Plastic and Reconstructive Surgery 90(5): 787-793.

11. Yoshimura M, Shimada T, Hosokawa M (1980) The vasculature of the peroneal tissue transfer. Plastic and Reconstructive Surgery 85(6): 917921.

12. Broer PN, Tanna N, Franco PB, Thanik VD, Levine SM, et al. (2013) Tenyear evolution utilizing computer-assisted reconstruction for giant ameloblastoma. J Reconstr Microsurg 29(3): 173-180. 
(c) (i) This work is licensed under Creative Submission Link: https://biomedres.us/submit-manuscript.php

$\begin{array}{ll}\text { BIOMEDICAL } & \text { Assets of Publishing with us } \\ \text { RESEARCHES } & \text { - Global archiving of articles } \\ \text { - Immediate, unrestricted online access } & \text { - Rigorous Peer Review Process } \\ & \text { - Authors Retain Copyrights } \\ & \text { https://biomedres.us/ }\end{array}$

